\title{
Swyer-James-MacLeod Syndrome: A case report in an adult and review of the literature
}

\author{
Eduardo Lening Trejo, Christian T. Le, Gary Weinstein, Patrick Barr, Mark Feldman \\ Texas Health Presbyterian Dallas Internal Medicine Residency Program, Texas, United States
}

Received: August 23, 2018

DOI: $10.5430 /$ crim.v5n $4 \mathrm{p} 23$

\author{
Accepted: October 17, 2018 \\ Online Published: October 30, 2018 \\ URL: https://doi.org/10.5430/crim.v5n4p23
}

\begin{abstract}
Swyer-James-MacLeod Syndrome (SJMS) is a rare, unilateral lung disease represented by radiographic translucency of the lung parenchyma secondary to the diminution of the pulmonary vasculature and to the overdistention of the alveoli. It is an uncommon sequela of post-infectious bronchiolitis obliterans (BO) in childhood. Patients with SJMS are often diagnosed in childhood and typically present with recurrent respiratory tract infections. Symptoms during childhood can be mild or absent, leading to a delayed diagnosis in adulthood. SJMS is characterized by the destruction of the small bronchioles and agenesis or hypoplasia of the pulmonary arteries leading to hypoperfusion of the pulmonary parenchyma, resulting in characteristic chest imaging findings of unilateral hyperlucency or translucence. Swyer and James first described this syndrome in 1953. It is a rare disease that can be can be caused by an infection with adenoviruses (types 3, 7, or 21) or Bordetella pertussis, a foreign body in the airway and hydrocarbon inhalation. We present a case of SJMS in whom the adult patient had been misdiagnosed with chronic obstructive pulmonary disease (COPD). She was eventually diagnosed with SJMS based on chest X-ray and chest CT findings of unilateral lung hyperlucency, as well as with scintigraphic findings showing virtually absent perfusion to the left lower lobe of the lung.
\end{abstract}

Key Words: Swyer-James-MacLeod Syndrome, Unilateral Hyperlucent Lung Syndrome

\section{Case presentation}

A 64-year-old woman presented to the emergency department with a two-week history of worsening shortness of breath and a productive cough. Prior to presenting to our facility, she had been prescribed doxycycline at an urgent care facility for a presumed respiratory tract infection. Her symptoms worsened, prompting her to seek further care.

Her medical history was notable for hypertension and chronic obstructive pulmonary disease (COPD). She reported a history of recurrent bronchitis since childhood. She was a former smoker with a 15 pack-year smoking history and, three years ago, was diagnosed with COPD by her primary care physician. Her medications included inhaled albuterol, tiotropium, and combination formoterol/budesonide.

On physical exam, her $\mathrm{O}_{2}$ saturation was $92 \%$ on 3 liters $\mathrm{O}_{2}$ per minute via nasal cannula. She appeared comfortable and in no acute distress. Chest exam revealed diminished expansion of the left chest and with nearly absent breath sounds in the left chest. The left chest was hyperresonant to percussion. Rales were noted in the left upper lobe area. There was no clubbing present. The remainder of the exam was unremarkable.

She received inhaled bronchodilator therapy consisting of albuterol for a presumed COPD exacerbation and was continued on doxycycline. A chest X-ray (see Figure 1) demonstrated a hyperinflated left lung field with rightward medi-

*Correspondence: Eduardo Lening Trejo; Email: eduardotrejomd@gmail.com; Address: 8200 Walnut Hill Lane, Dallas, TX, 75231, United States. 
astinal shift and compression of the right lung. The CT chest images (see Figure 2) demonstrated hyperlucency of the left lung field with the heart and mediastinum deviated to the right. There were small pleural effusions, with the left one larger than the right. A ventilation lung scan with Xenon133 demonstrated markedly diminished ventilation of the left lung compared to the right (see Figure 3). Perfusion lung scan using Single Photon Emission Computed Tomography (SPECT) demonstrated virtually absent perfusion to the anatomic left lower lobe (see Figure 4). She underwent preoperative pulmonary function analysis and was found to have a forced vital capacity (FVC) of 1.35 liters (45\% of predicted) and a forced expiratory volume at one second $\left(\mathrm{FEV}_{1}\right)$ of 0.55 liters ( $25 \%$ of predicted) with an $\mathrm{FEV}_{1} / \mathrm{FVC}$ ratio of $40 \%$. The total lung capacity (TLC) was 8.68 liters, the residual volume (RV) was markedly elevated at 7.24 liters, and the RV/TLC ratio was $83 \%$.

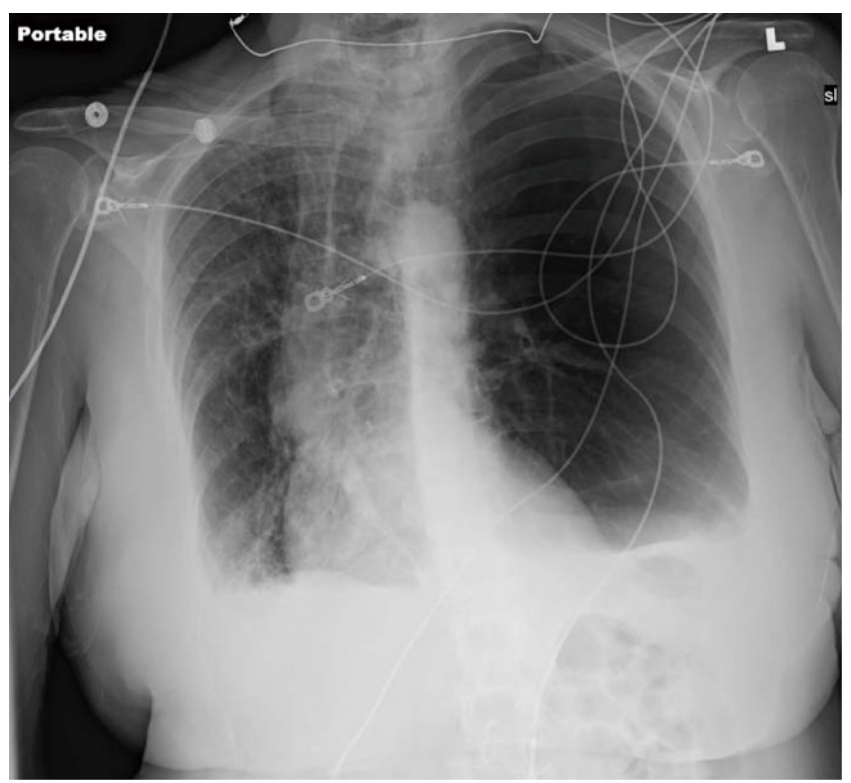

Figure 1. Chest radiograph with a hyperinflated left lung field. Note rightward mediastinal shift and compression of the right lung.

The consulting cardiothoracic surgeon recommended a left lower lobectomy. At thoracotomy, the left lower lobe was found to be enlarged and emphysematous with some adhesions. The left pleural surface was focally torn consistent with a large torn bleb of $4.5 \mathrm{~cm}$ in the greatest dimension. The histologic sections from the left lower lobe demonstrated emphysematous lung parenchyma with focal congestion, reactive changes, and mild chronic inflammation (see Figure 5). The inflammatory cells consisted predominantly of lymphocytes and histiocytes. Her hospital stay was complicated by a pneumothorax with an air leak that caused extensive subcutaneous emphysema. The air leak resolved with conservative management. Upon discharge, the patient noted an improved ability to breath and there was resolution of her hypoxemia.

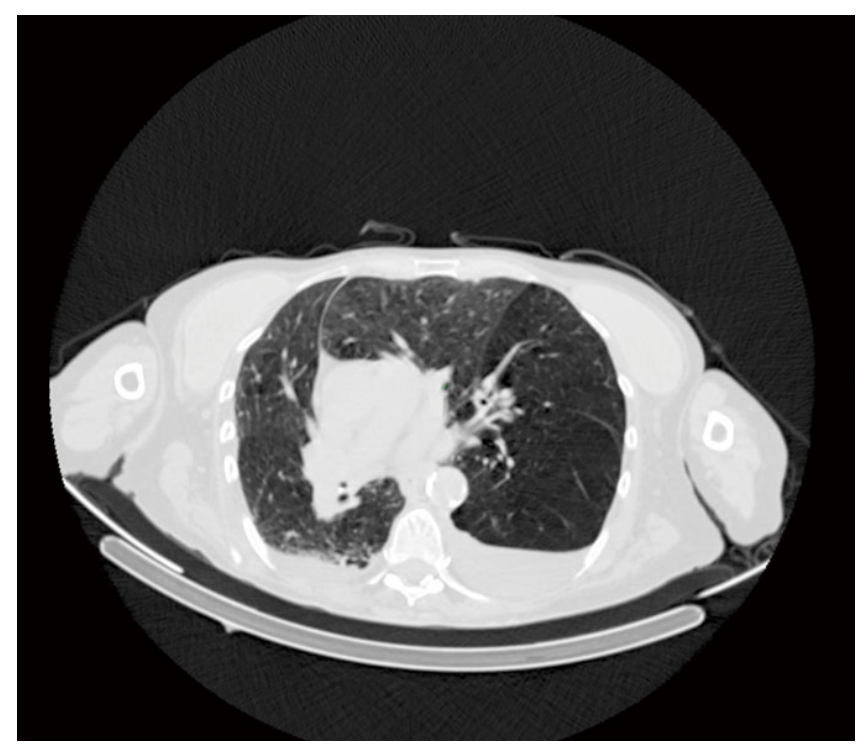

Figure 2. Chest CT. Note hyperlucency of the left lung, with the heart and mediastinum deviated to the right. There were small bilateral pleural effusions.

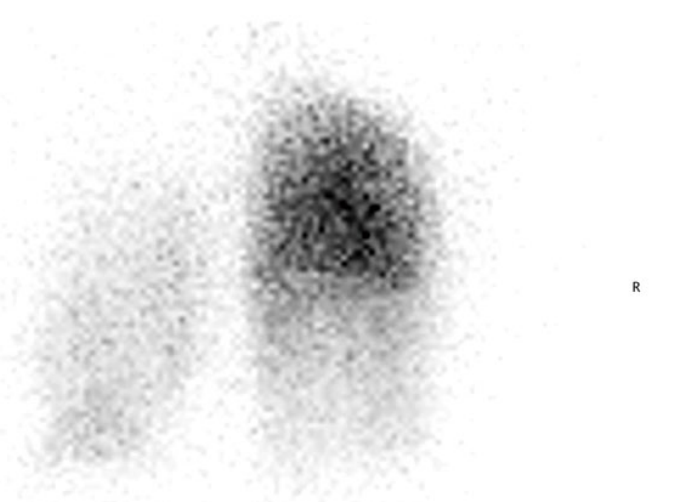

Figure 3. Ventilation lung scan with Xenon-133. Note the markedly diminished ventilation of the left lung compared to the right (posterior projection, patient's left lung on the left). Decreased right lower lobe ventilation is secondary to regional atelectasis. $\mathrm{R}$, right; $\mathrm{L}$, left.

Sixty days following her lung resection, she presented for follow up and reported greatly improved quality of life and indicated that she felt better than she had in the last 2 decades. Post-operative pulmonary function tests were performed and 
compared to the pre-operative pulmonary function tests. Her forced vital capacity improved from 1.35 liters ( $45 \%$ of predicted) to 3.06 liters (83\% of predicted). Her forced expiratory volume at one second improved from 0.55 liters $(25 \%$ of predicted) to 1.39 liters ( $49 \%$ of predicted).

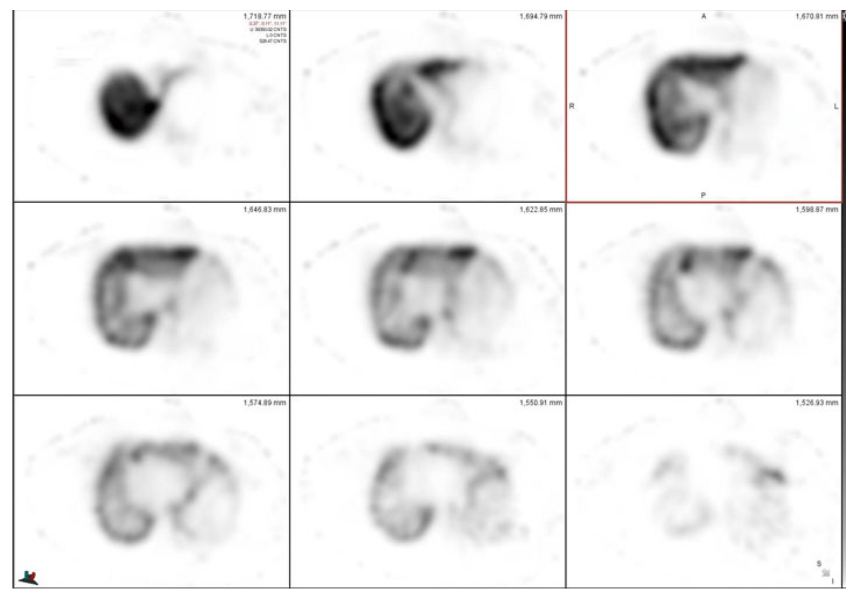

Figure 4. Perfusion lung scan, selected cross sectional SPECT (Single Photon Emission Computed Tomography) images. Note the amount of perfusion to the anatomic left lower lobe is virtually absent. A, anterior; $\mathrm{P}$, posterior; $\mathrm{R}$, right; L, left.

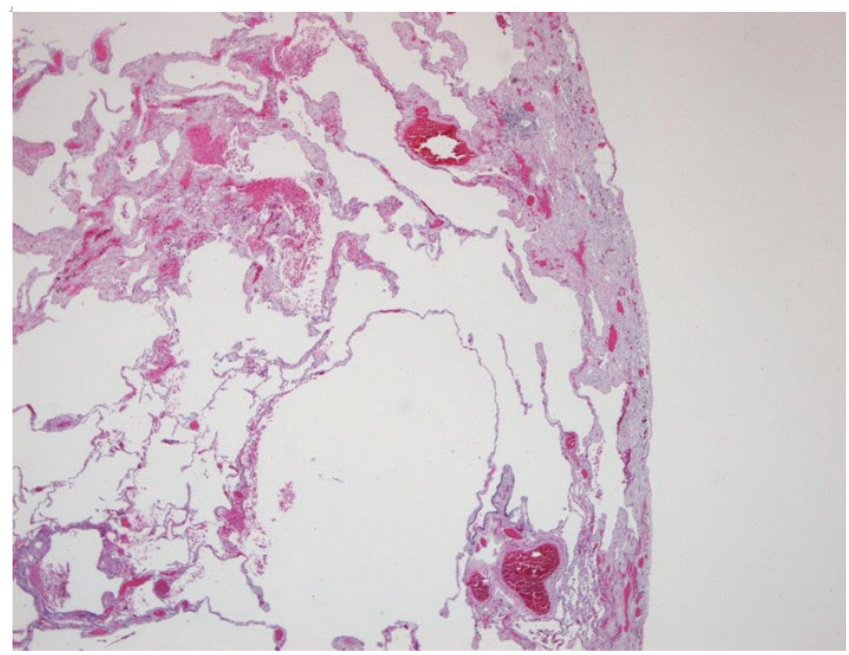

Figure 5. Low power hematoxylin and eosin stained section from the resected left lower lobe demonstrating emphysematous lung parenchyma with focal congestion, reactive changes, and mild chronic inflammation.

\section{Discussion}

Swyer-James-MacLeod Syndrome (SJMS) is a rare, emphysematous pulmonary illness represented by radiographic translucency of the lung parenchyma secondary to the diminution of the pulmonary vasculature and to the overdistention of the alveoli. ${ }^{[1]}$ SJMS has not been shown to increase mortality. ${ }^{[2]}$ It was first characterized by Paul R. Swyer and G.C.W. James in 1953 when they published a case report of a 6-year-old boy with unilateral pulmonary emphysema. Macleod in 1954 reported on 9 cases of abnormal transradiancy of the lung. ${ }^{[3]}$ The main features that Macleod described were lessening of the breath sounds and abnormal transradiancy of one lung. ${ }^{[4]}$ SJMS is usually diagnosed in childhood. SJMS is a rare condition in childhood, occurring in $3.8 \%-4.3 \%$ of children with post-infectious BO. ${ }^{[5]}$ Affected patients typically present with recurrent respiratory tract infections. There has been disagreement regarding the etiology (etiologies) of SJMS. It is considered a rare sequela of post-infectious $\mathrm{BO}$ and pneumonitis from infections with adenoviruses (types 3, 7, and 21) or with Bordetella pertussis. Non-infective causes of SJMS include foreign body aspiration, inhalation of toxic fumes and hydrocarbon inhalation. ${ }^{[1,2,6]}$

SJMS is characterized by the narrowing and obliteration of the small bronchioles and hypoplasia of the pulmonary arteries leading to hypoperfusion of the pulmonary parenchyma. ${ }^{[1,2]}$ The vascular damage takes place throughout childhood and impedes the expected formation of the alveolar ducts. ${ }^{[6]}$ Post-infectious BO results in inflammation and submucosal fibrosis in the airways and leads to airway distortion and occlusion with the diseased distal bronchioles and their lung sacs becoming hyperinflated. ${ }^{[2,6]}$ Destruction of the pulmonary capillary bed and decreased circulation to the principle pulmonary artery segment is caused by the fibrosis of the interalveolar septae. ${ }^{[2]}$ Overexpansion of the terminal sacs due to obstruction of the bronchioles of the distal airways increases resistance to blood flow through the alveolar capillaries and leads to deterioration of the vasculature. ${ }^{[2]}$ This results in the characteristic chest imaging findings of unilateral hyperlucency or translucence. Some patients have panacinar emphysematous changes. ${ }^{[7]}$

Symptoms are nonspecific and can be mild or absent during childhood, leading to a delayed diagnosis in adulthood. Adult patients present with productive cough, shortness of breath on exertion, hemoptysis, reduced exercise tolerance, and lung infections that can be frequent and recurrent. ${ }^{[6]}$

Diagnosis of SJMS is made incidentally in some cases. ${ }^{[6]}$ Adult patients with SJMS are frequently identified after a radiography of the chest, oftentimes acquired for another reason, demonstrates a unilateral hyperlucency. ${ }^{[1]}$ It is essential to exclude other sources of unilateral hyperlucency such as congenital lobar emphysema, bronchogenic cyst, pneumotocele, bronchiectasis with air trapping and emphysema 
secondary to bronchial stenosis or bronchospasm. ${ }^{[1]}$ Poland syndrome can present as unilateral transradiancy, but this syndrome is caused by a congenital and unilateral absence of the chest muscles including the pectorals major and minor muscles as well as the decreased development of the breast and nipple with associated diminished subcutaneous tissue. ${ }^{[6]}$

A triad has been proposed to confirm the diagnosis of SJMS. ${ }^{[10]}$ First is a chest $\mathrm{X}$-ray, chest CT or high resolution chest $\mathrm{CT}$ that demonstrates a lung with hyperlucency occurring unilaterally, a small ipsilateral hilum and pulmonary artery, as well as air trapping on expiration. ${ }^{[10]}$ Displacement of the mediastinum away from the afflicted lung may also be present, as in our case. ${ }^{[9]}$ The increased lucency is frequently observed in one lobe or lung and, as in our patient, the left lung appears to be the primary afflicted lung in the majority of patients. ${ }^{[6,8]}$ CT scan findings can include air trapping manifesting as persistent low attenuation of the lung tissues and may demonstrate bronchiectasis, bronchiolectasis, atelectasis and scarring. ${ }^{[9]} \mathrm{CT}$ is more sensitive than radiography in distinguishing pulmonary regions with hyperlucency and is superior in detecting the degree and distribution of the disorder. $^{[9]}$ The second and third components of the triad are a decrease in ventilation of the afflicted lung along with matching decreased lung perfusion, recognized as ipsilateral pruned-tree appearance on angiography or parallel defects on ventilation/perfusion (V/Q) scan. ${ }^{[1]}$ Air-trapping can often be demonstrated in the washout phase of the ventilation component of the V/Q scan. ${ }^{[1]}$

Pulmonary angiography, not required for diagnosis of SJMS, can demonstrate hypoplasia and reduction in the size of the affected pulmonary vasculature. ${ }^{[6]}$ SJMS is usually managed conservatively by treating current and preventing subsequent pulmonary infections. ${ }^{[12]}$ Vaccinations, including the influenza and pneumococcal vaccines, should be provided.
Surgical procedures may be indicated should patients experience recurrent infections in the affected lung segments; however, a surgical approach should be reserved when optimized medical management has failed. ${ }^{[1,9,13]}$ The majority of surgically treated patients undergo pneumonectomy, although some are treated with lobectomy or segmentectomy. ${ }^{[13]}$ Most patients who undergo surgical treatment are adults. ${ }^{[12]} \mathrm{Pa}-$ tients can be classified into the following clinical categories regarding surgical indications: (1) subjects with frequent and periodic infections that do not improve with conservative management; (2) subjects with clinical decline that results in failure to thrive; and (3) subjects who present with spontaneous or repetitive pneumothorax. ${ }^{[1]}$ Lung volume reduction surgery (LVRS) is a possible surgical option and is based on the convention that the mechanics of the diaphragm, chest wall, and airways can be improved by the reduction in the amount of air trapping and reducing the lung volumes. ${ }^{[13]}$ Tasaki and associates hypothesized that LVRS could theoretically augment lung function regardless of the nature of the condition causing hyperinflation. ${ }^{[13]}$ They report on a successfully executed LVRS in a 14-year-old patient with SJMS. ${ }^{[13]}$

\section{Conclusion}

Our patient had been misdiagnosed with COPD. She was eventually diagnosed with SJMS at the age of 64 based on chest X-ray and chest CT findings of unilateral hyperlucency and scintigraphic findings of virtually absent ventilation and perfusion to the left lower lobe. Treatment of SJMS includes the early control of infections as well as appropriate vaccinations. In uncommon cases, patients with SJMS can be managed by lung resection, as in our case.

\section{Conflicts of INTERest Disclosure}

The authors have declared no conflicts of interest.

\section{REFERENCES}

[1] Panagopoulos N, Papavasileiou G. VATS bullectomy and apical pleurectomy for spontaneous pneumothorax in a young patient with Swyer-James-Macleod syndrome: Case report presentation and literature review focusing on surgically treated cases. Journal of Cardiothoracic Surgery. 2014; 9: 13. PMid:24410793. https: //doi.org/10.1186/1749-8090-9-13

[2] Patel J, Chang C. New diagnosis of Swyer-James-Macleod Syndrome in an adult: A case report. American Journal of Respiratory and Critical Care Medicine. 2016; 193: A3607.

[3] Swyer PR, James GCW. A case of unilateral pulmonary emphysema. Thorax. 1953; 8: 133-136. PMid:13077508. https://doi.org/10 $.1136 /$ thx.8.2.133

[4] Macleod WM. Abnormal transradiancy of one lung. Thorax. 1954; 9: 147-153. PMid:13179127. https://doi.org/10.1136/thx. 9.2 .147
[5] Abba AA, Al-Mobeireek AF. Clinical spectrum of Swyer-JamesMacleod syndrome in adults. Saudi Med J. 2003; 24(2): 195-198. PMid:13179127.

[6] Dirweesh A, Alvarez C, Khan M, et al. A unilateral hyperlucent lung - Swyer-James syndrome: A case report and literature review. Respir Med Case Rep. 2017; 20: 104-106. https ://doi.org/10.1016/ j.rmcr. 2017.01 .004

[7] Khalil KF, Saeed W. Swyer-James-Macleod syndrome. J Coll Phys Surg Pak. 2008; 18: 190-192. PMid:18460255.

[8] Moore AD, Godwin JD, Dietrich PA, et al. Swyer-James syndrome: CT finding in eight patients. Am. J. Roentegenol. 1992; 158: 12111215. PMid:1590109. https://doi .org/10.2214/ajr.158.6. 1590109

[9] Singal KK, Bhatti KP, Gupta A, et al. Swyer-James-MacLeod Syndrome: A rare case. Bangladesh J Med Sci. 2015; 14: 402. https://doi.org/10.3329/bjms.v14i4.20407 
[10] Lucas de SPS, Lopes R, Neo HM. Swyer-James-MacLeod syndrome in a surgically treated child: A case report and brief literature review. J Pediatr Surg. 2012; 47(2): e17-e22. PMid:22498410. https://doi.org/10.1016/j.jpedsurg. 2011.12.011

[11] Arslan N, Ilgan S, Ozkan M, et al. Utility of ventilation and perfusion scan in the diagnosis of young military recruits with an incidental finding of hyperlucent lung. Nucl Med Commun. 2001; 22(5): 525530. PMid:11388574. https://doi .org/10.1097/00006231-2 00105000-00010
[12] Mehra S, Basnayake T, Falhammar H, et al. Swyer-James-MacLeod syndrome - a rare diagnosis presented through two adult patients. Resp Case Rep. 2017 Sep; 5(5): e00245. PMid:28638618. https : //doi.org/10.1002/rcr2.245

[13] Tasaki A, Nakanishi R. Lung volume reduction surgery for a professional athlete with Swyer-James Syndrome. The Annals of Thoracic Surgery. 2005 July; 80(1): 342-344. PMid:15975405. https : //doi.org/10.1016/j.athoracsur.2003.12.017 